\title{
Suppression of ionic doping by molecular dopants in conjugated polymers for improving specificity and sensitivity in biosensing applications
}

Hyun-June Jang, Yunjia Song, Justine Wagner, Howard E. Katz

Department of Materials Science and Engineering, Johns Hopkins University, 3400 N. Charles St, Baltimore, MD 21218-2608, USA

\section{Supporting Information}




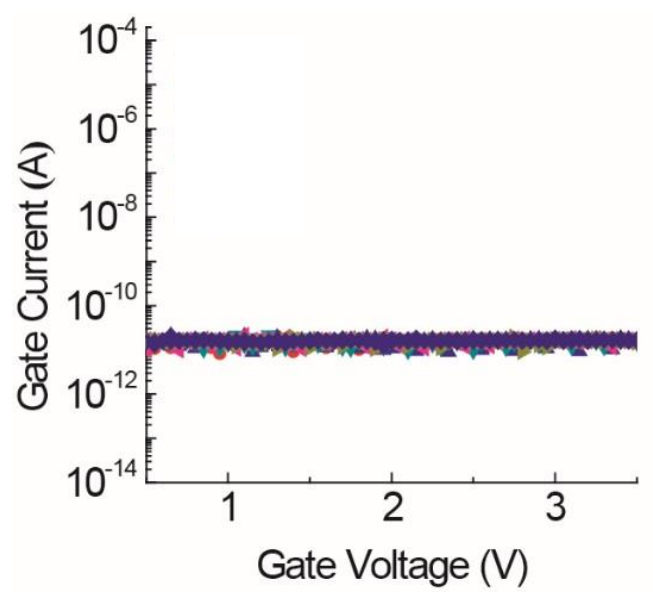

Figure S1. Gate current of the RGFET with $\mathrm{SiO}_{2} \mathrm{RG}$ under a $\mathrm{pH} 7$ solution. Gate current is repeatedly measured 10 times while no significant change is observed. 


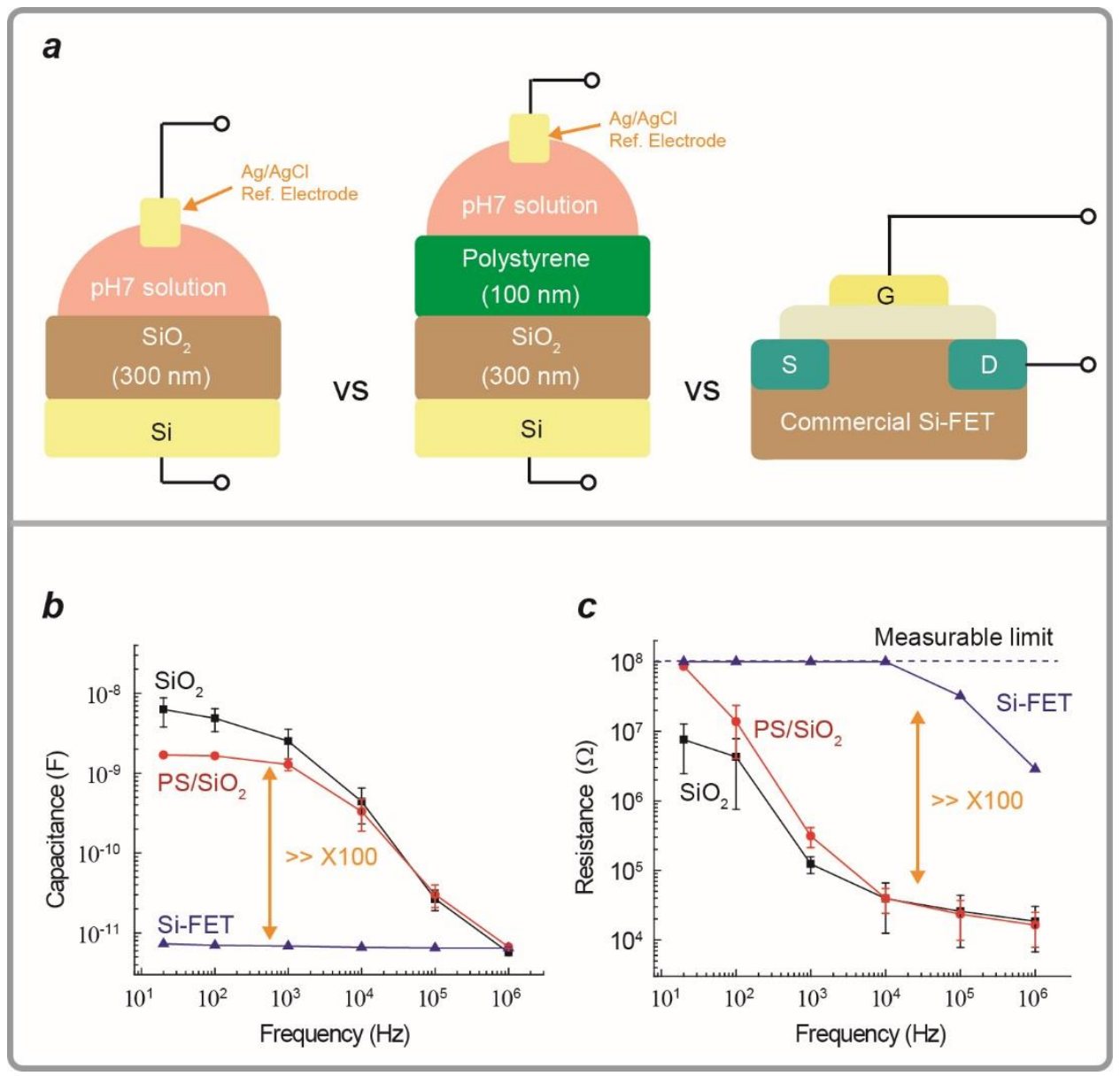

Figure S2. (a) Schematic image of impedance measurement setups of RGs and Si-FET. Impedance of the $\mathrm{RG}$ and Si-FET is measured individually. Two types of the $\mathrm{RG}$ structure are prepared: A $300 \mathrm{~nm}$ thick $\mathrm{SiO}_{2}$ and $100 \mathrm{~nm}$ thick polystyrene on $300 \mathrm{~nm} \mathrm{SiO}_{2}$ are each tested. $\mathrm{Ag} / \mathrm{AgCl}$ reference electrode is used to apply electric fields over the RG structure. The same volume of $\mathrm{pH} 7$ solution $(50 \mu \mathrm{L})$ is added on each $\mathrm{SiO}_{2}$ and $\mathrm{PS} / \mathrm{SiO}_{2}$. For the volume of $50 \mu \mathrm{L}$, a large diameter of solution of over $0.5 \mathrm{~cm}$ is achieved on $\mathrm{RG}$ surfaces. $\mathrm{AC}$ frequency is applied between the $\mathrm{Ag} / \mathrm{AgCl}$ reference electrode and the $\mathrm{Si}$ electrode at the bottom of each RG. The voltage level is set at $1 \mathrm{~V}$ during the measurement of capacitance and resistance. At least 3 samples of each RG were measured. At the same measurement condition, the impedance of the commercial MOSFET is measured by using two terminals from the drain to the gate. Frequency vs (b) capacitance and (c) resistance from $\mathrm{RGs}$ of $\mathrm{SiO}_{2}$ and $\mathrm{PS} / \mathrm{SiO}_{2}$ and $\mathrm{Si}-\mathrm{FET}$. 
Capacitance and resistance from both RGs are compared with that of the MOSFET as shown in Figure $\mathrm{S} 1 \mathrm{~b}$ and $\mathrm{S} 1 \mathrm{c}$, respectively. $\mathrm{PS} / \mathrm{SiO}_{2} \mathrm{RG}$ has a lower capacitance than that $\mathrm{SiO}_{2}$ due to the deposition of thick PS layer on $\mathrm{SiO}_{2}$. Also, the PS has even lower dielectric constant (2.56) of that of $\mathrm{SiO}_{2}$ (3.9). Nonetheless, the capacitance of the MOSFET is at least 100 times smaller than any RG surfaces (Figure S1b). The total capacitive system over the RGFET is mostly determined by that of the MOSFET.

The resistance of the MOSFET is also much larger than those of RGs (Figure S1c). The gate voltage applied over the RGFET system is mostly dropped to the MOSFET. These results indicate that effects of the impedance of RGs on the total impedance of the RGFET are essentially insignificant.
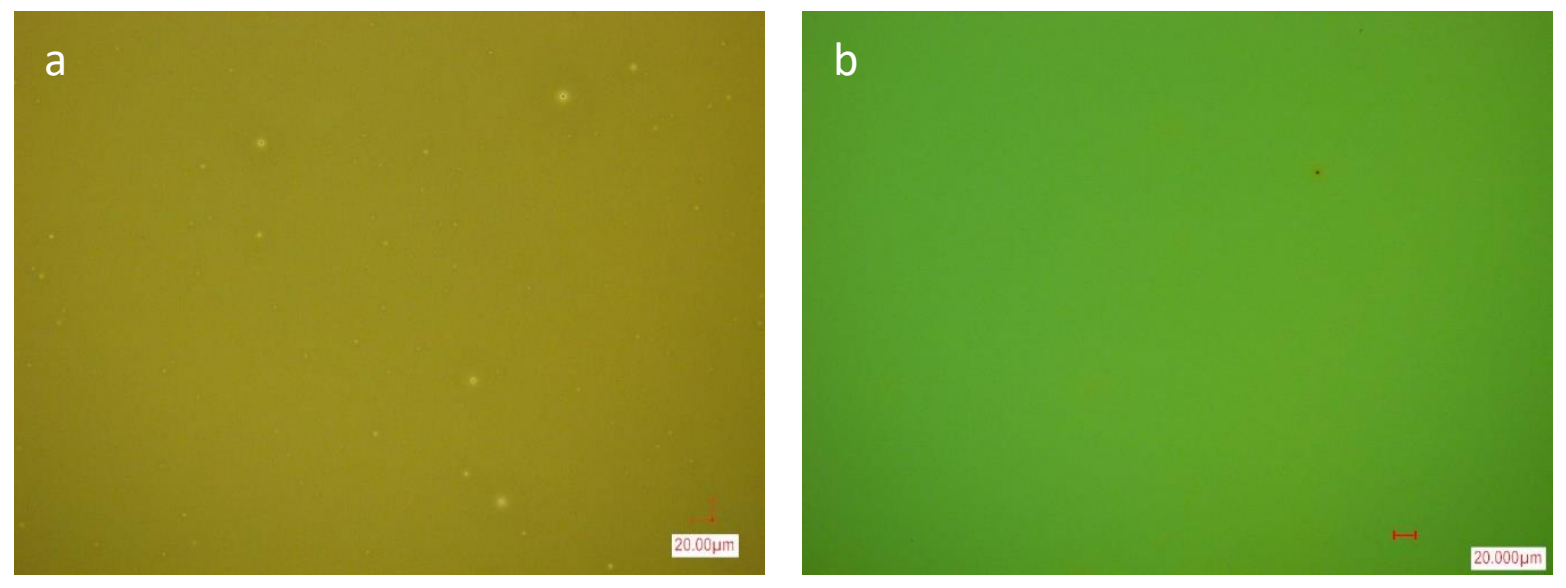

Figure S3. Optical surface images of (a) P3HT and (b) PT-COOH layer on $\mathrm{SiO}_{2}$ substrate. 

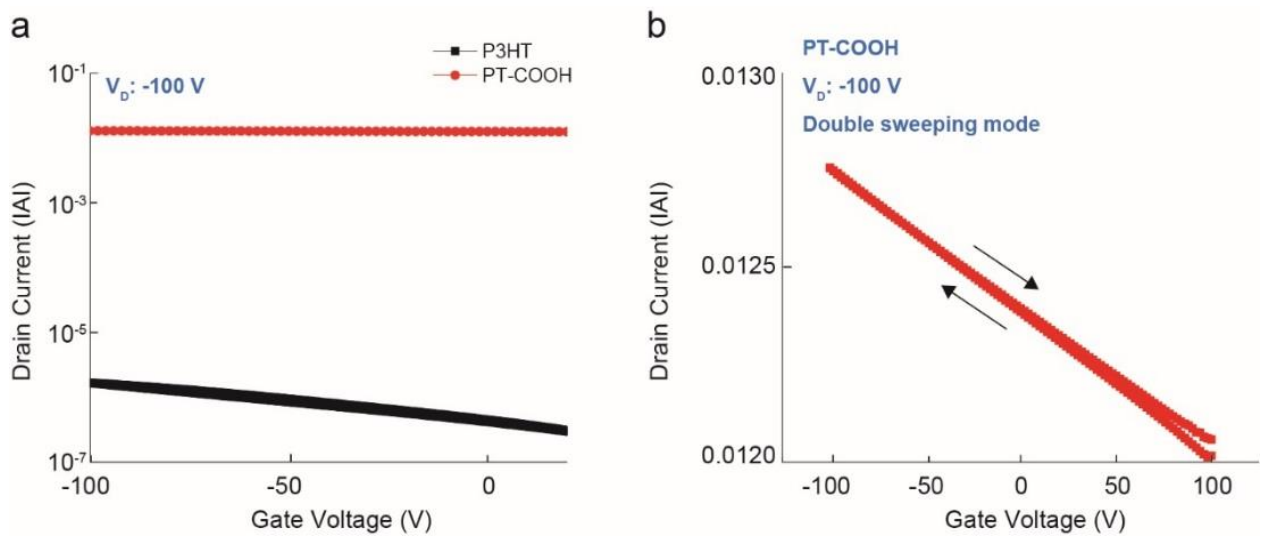

Figure S4. (a) Representative transfer curve of organic field-effect transistors (OFETs) with P3HT and PT$\mathrm{COOH}$ channel without doping. $300 \mathrm{~nm}$-thick $\mathrm{SiO}_{2}$ and $\mathrm{Si}$ are used as a gate oxide and a gate electrode, respectively. $30 \mathrm{~nm}$-thick Au is used for source and drain of OFETs. (b) Linear plot of transfer curve of the PT-COOH OFET. Less gate modulation is shown in PT-COOH possibly due to the high concentrations of hole carriers in the PT-COOH film.

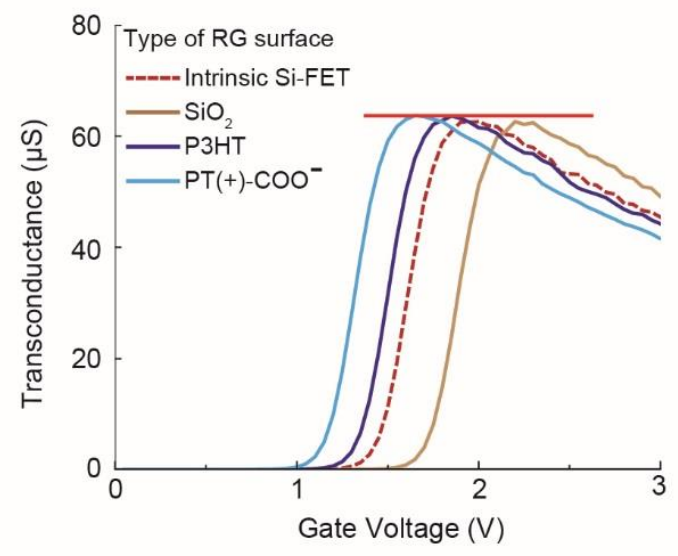

Figure S5. Transconductance of transfer curves in Figure 1b. Insignificant difference in transconductances is shown over all RGFETs with the $\mathrm{RG}$ of $\mathrm{SiO}_{2}, \mathrm{P} 3 \mathrm{HT} / \mathrm{SiO}_{2}$, and $\mathrm{PT}(+)-\mathrm{COO}^{-} / \mathrm{SiO}_{2}$. Substhreshold swing of intrinsic Si-FET is calculated to be $136 \mathrm{mV} / \mathrm{dec}$. The RGFETs show 137, 134, and $135 \mathrm{mV} / \mathrm{dec}$ for $\mathrm{SiO}_{2}$, $\mathrm{P} 3 \mathrm{HT} / \mathrm{SiO}_{2}$, and $\mathrm{PT}(+)-\mathrm{COO}^{-} / \mathrm{SiO}_{2} \mathrm{RG}$, respectively. 

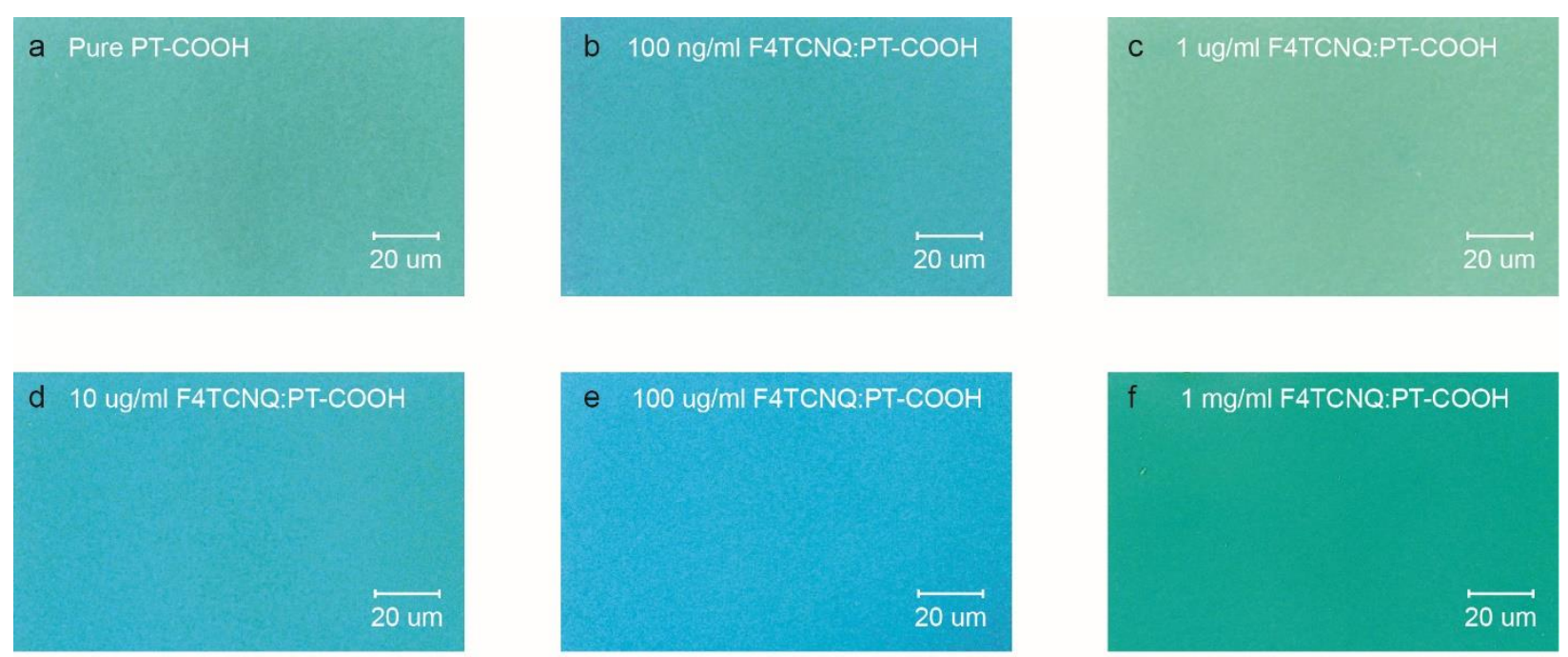

g

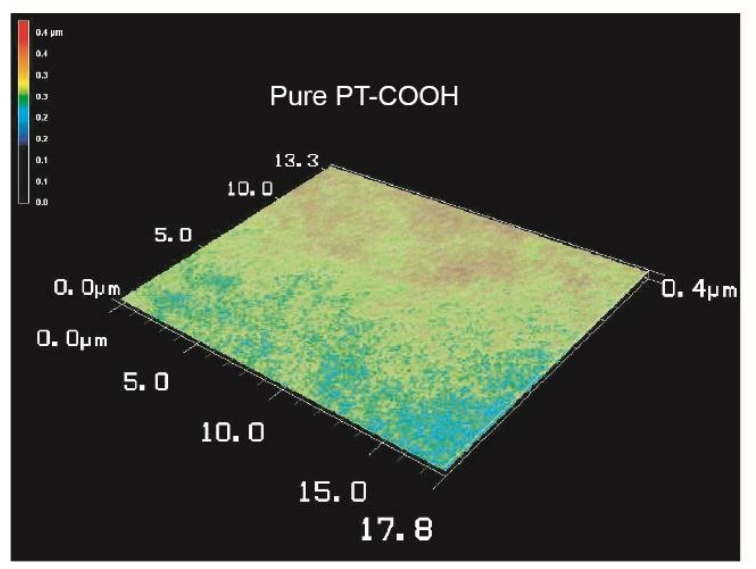

$\mathrm{h}$

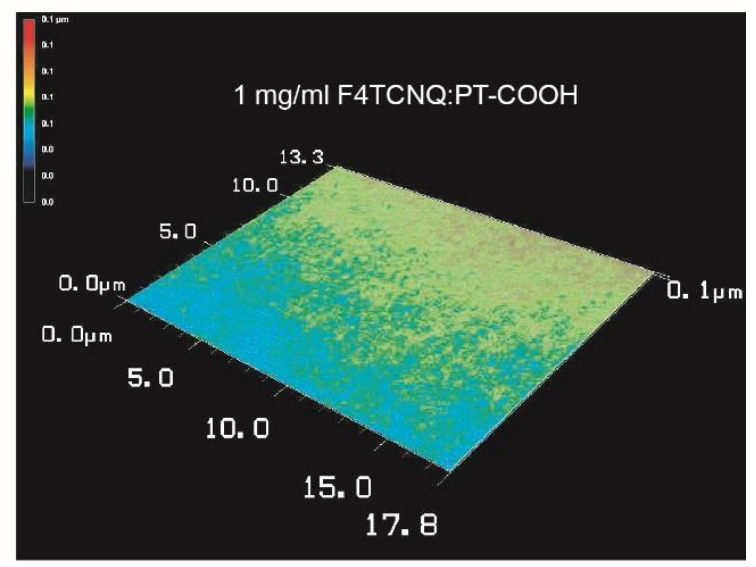

Figure S6. Microscopic images of PT-COOH surfaces sequentially doped by different concentrations of F4TCNQ solution: (a) Pure PT-COOH film, (b) 100 ng/ml F4TCNQ:PT-COOH film, (c) $1 \mu \mathrm{g} / \mathrm{ml}$ F4TCNQ:PT-COOH film, (d) $10 \mu \mathrm{g} / \mathrm{ml} \mathrm{F4TCNQ:PT-COOH} \mathrm{film,} \mathrm{(e)} 100 \mu \mathrm{g} / \mathrm{ml}$ F4TCNQ:PT-COOH film, and (f) $1 \mathrm{mg} / \mathrm{ml}$ F4TCNQ:PT-COOH film. Each F4TCNQ solution placing at the pure PT-COOH film was spin-coated at 1500 RPM for $1 \mathrm{~min}$. 3-dimensional images of surfaces of (g) the pure PT-COOH and (h) 1 mg/ml F4TCNQ:PT-COOH film characterized by LASER microscopy (Keyence 3D Laser Scanning Microscope VK-X100/X200 Series). No significant changes in morphology were observed from the sequential doping method. 

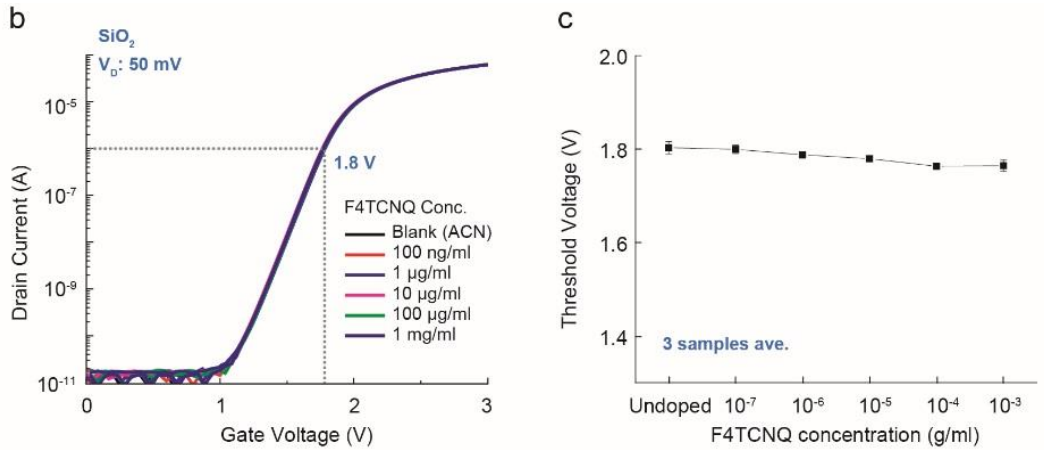

Figure S7. (a) Schematic image of RGFET with $\mathrm{SiO}_{2}$ RG. (b) Representative transfer curves of the RGFET with $\mathrm{SiO}_{2} \mathrm{RG}$ responding to increased F4TCNQ concentrations in a range from $100 \mathrm{ng} / \mathrm{ml}$ to $1 \mathrm{mg} / \mathrm{ml}$. (c) $\mathrm{V}_{\text {th }}$ distributions over 3 samples from the $\mathrm{SiO}_{2} \mathrm{RG}$ in terms of increasing F4TCNQ concentrations over time.

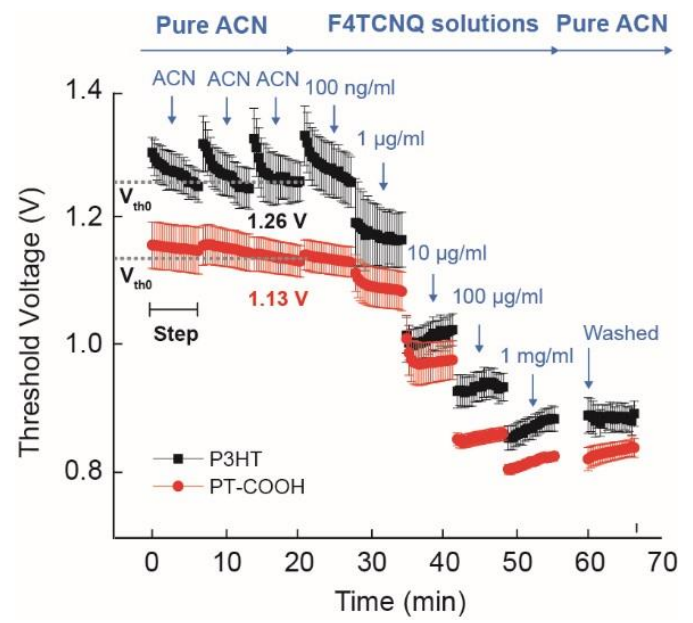

Figure S8. $\mathrm{V}_{\text {th }}$ distributions over at least 8 samples from P3HT and PT-COOH RGs in terms of increasing F4TCNQ concentrations over time. Each step includes twenty consecutive measurements taken at incremental times under a specific dopant concentration, in order to obtain stabilized $V_{\text {th }}$ levels at each solution, the last value of which is plotted in Figure 2c. The first three steps are measured under a refreshed pure ACN solution without injections of any dopant in RG surfaces for stabilization of the measurement system. Initial fluctuation in $\mathrm{V}_{\text {tho }}$ of $\mathrm{P} 3 \mathrm{HT}$ is shown at each step of stabilization while its $\mathrm{V}_{\text {tho }}$ is saturated near $1.26 \mathrm{~V}$. $\mathrm{V}_{\text {th } 0}$ of PT-COOH is more stably saturated near $1.13 \mathrm{~V}$. Rapid shifts in $\mathrm{V}_{\text {th }}$ are observed for 
both films in contact with F4TCNQ concentrations higher than $1 \mu \mathrm{g} / \mathrm{ml}$. Following all the dopant injections up to $1 \mathrm{mg} / \mathrm{ml} \mathrm{F4TCNQ}$ concentrations, each doped P3HT and PT-COOH surface is aggressively washed 3 consecutive times with the pure ACN.
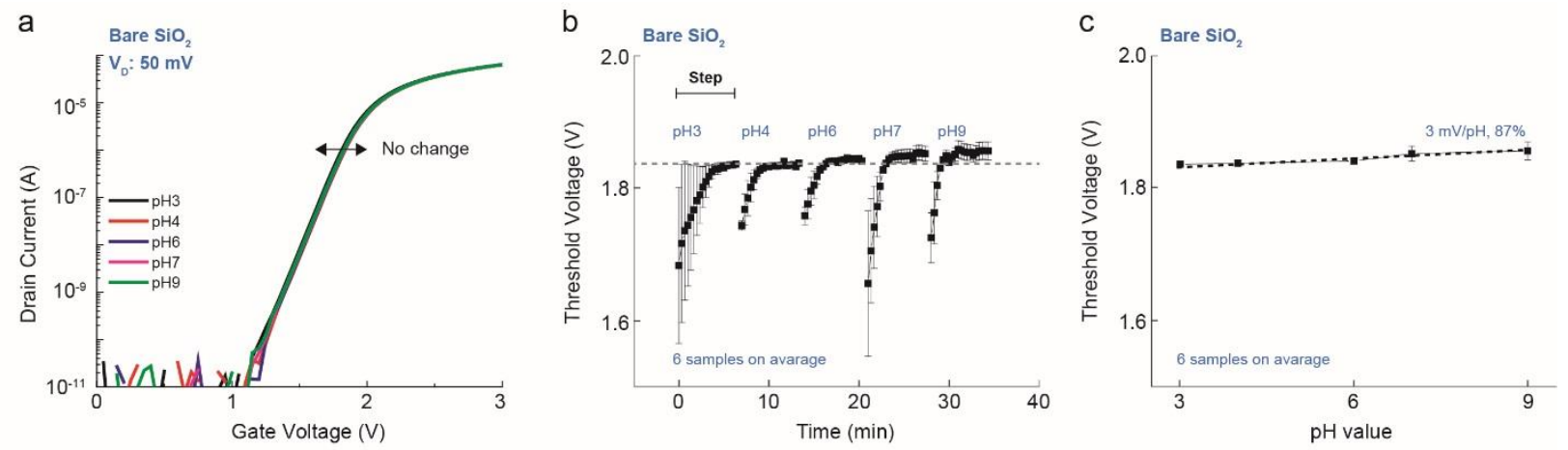

Figure S9. (a) Representative transfer curves of the RGFET with the $\mathrm{RG}$ of $\mathrm{SiO}_{2}$ that respond to $\mathrm{pH}$ solutions ranging from $\mathrm{pH} 3$ to 9. (b) $\mathrm{V}_{\text {th }}$ distributions at least 6 samples from $\mathrm{SiO}_{2} \mathrm{RGs}$ in terms of increasing $\mathrm{pH}$ values over time. Each step illustrated in Figure $\mathrm{S} 4 \mathrm{~b}$ includes twenty consecutive measurements taken at incremental times under a specific $\mathrm{pH}$ solution. Initial drift coming from hydration is saturated within measurements of each pH solution. (c) $V_{\text {th }}$ levels collected at the end of each step in Figure $\mathrm{S} 4 \mathrm{~b}$ as a function of $\mathrm{pH}$ values. $\mathrm{pH}$ sensitivity is calculated to be $3 \mathrm{mV} / \mathrm{pH}$ with $\mathrm{R}^{2}$ of $87 \%$. Average $\mathrm{V}_{\mathrm{th}}$ from each $\mathrm{pH}$ solution is used for calculation of $\mathrm{pH}$ sensitivity and linearity. 
a
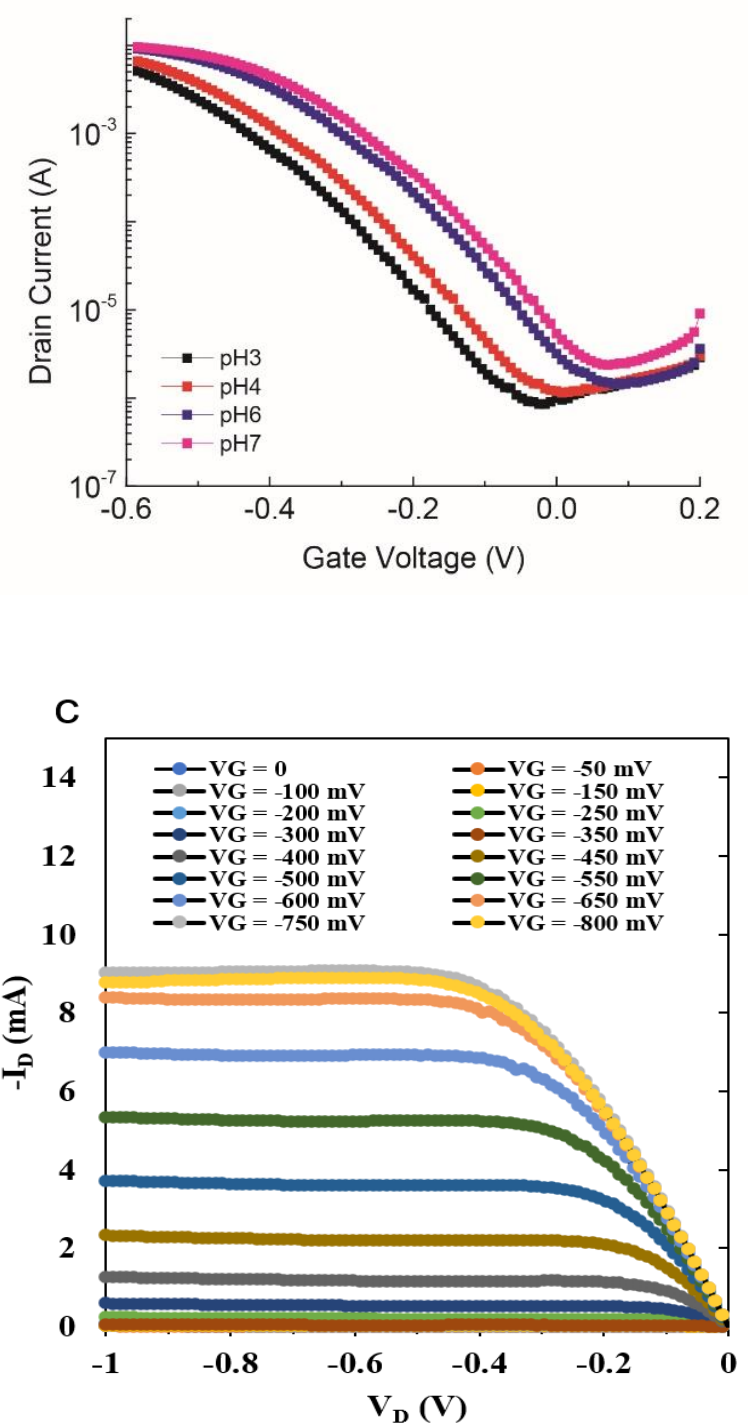

b

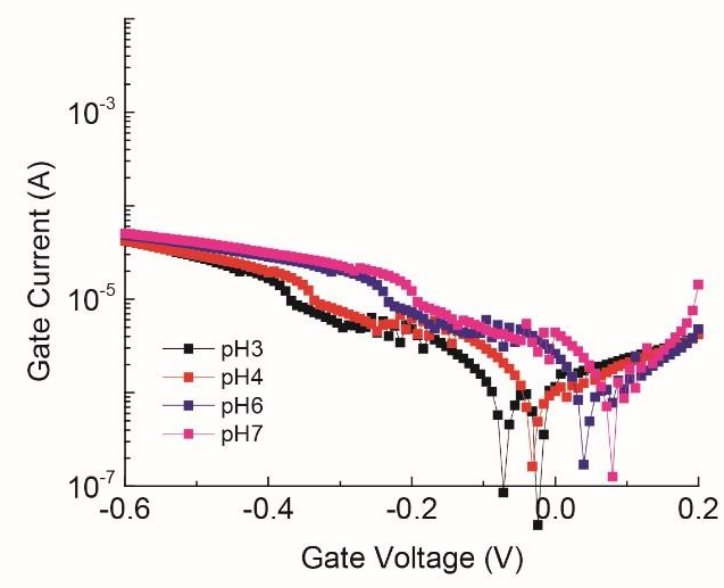

Figure S10. (a) Transfer curves of OECT device based PT-COOH. Drain voltage sets at - 0.2 V. Interdigital patterns of $150 \mathrm{~nm}$ thick Au was used for source and drain. Width and length of finger is $20 \mu \mathrm{m}$ and $1 \mathrm{~mm}$. A gap between finger is $10 \mathrm{um}$. Total 50 fingers are included in the interdigital pattern. $30 \mathrm{mg} / \mathrm{ml} \mathrm{PT-COOH}$ solution was spin-coated on the interdigital pattern. (b) Gate current levels of the OECT device in Figure S9a. (c) Output curves of the device. A related device characterization was published during the time of preparation of this manuscript: Khau, B.V.; Savagian, L.R.; De Keersmaeker, M.; Gonzalez, M.A.; Reichmanis, E.A. ACS Materials Lett. 2019, 1, 599-605. 


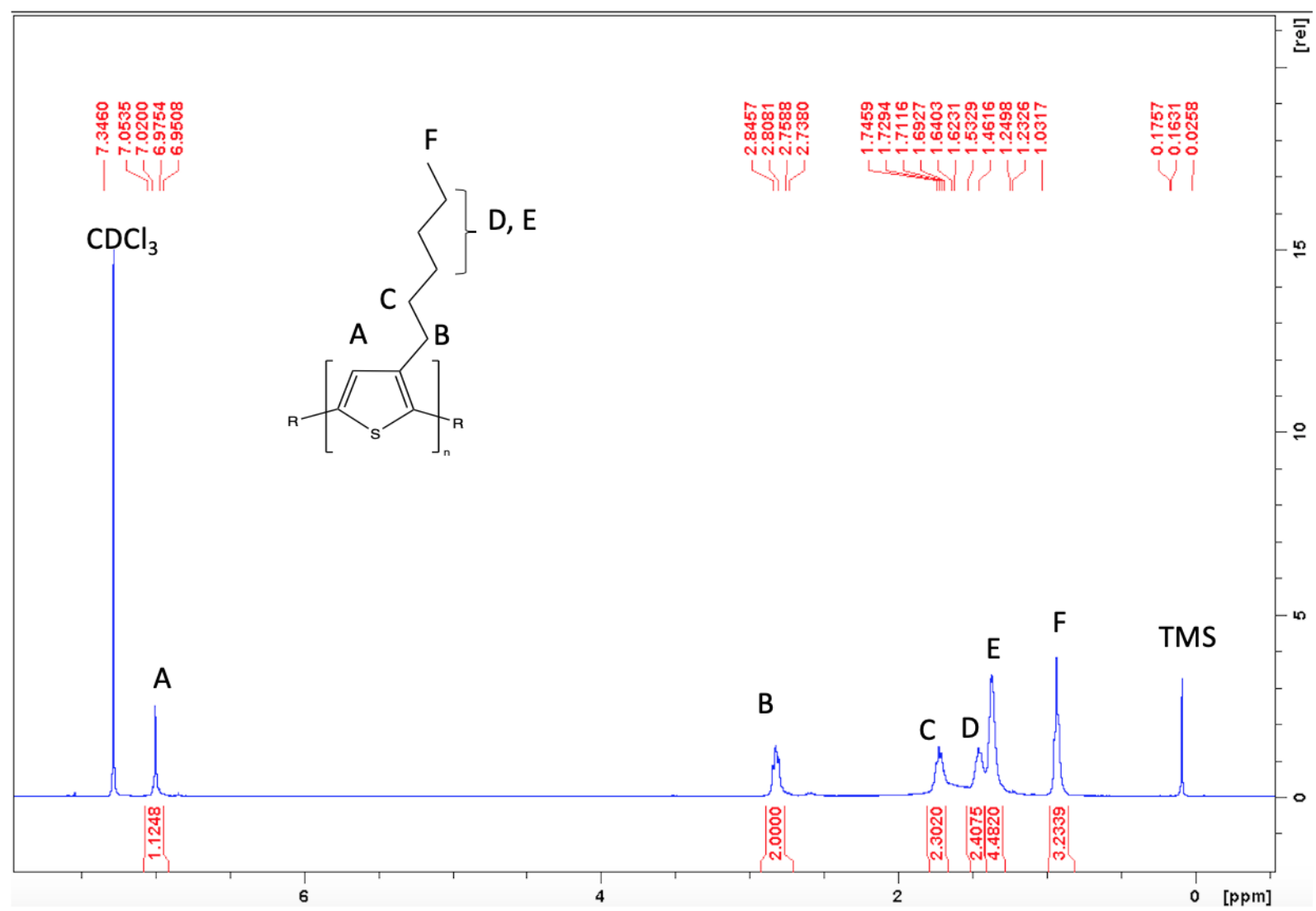

Figure S11. NMR Spectrum of P3HT. Yield: $60 \%, \mathrm{Mn}=7,638 ; \mathrm{Mw}=10,133$, and PDI $=1.33 .1 \mathrm{H} \mathrm{NMR}$

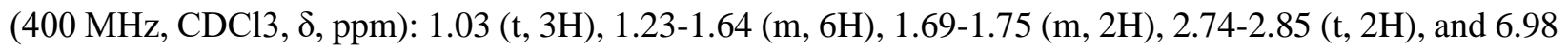
(s, 1H). 